\title{
Burnout and turnover intention among electronics manufacturing employees in South Africa
}

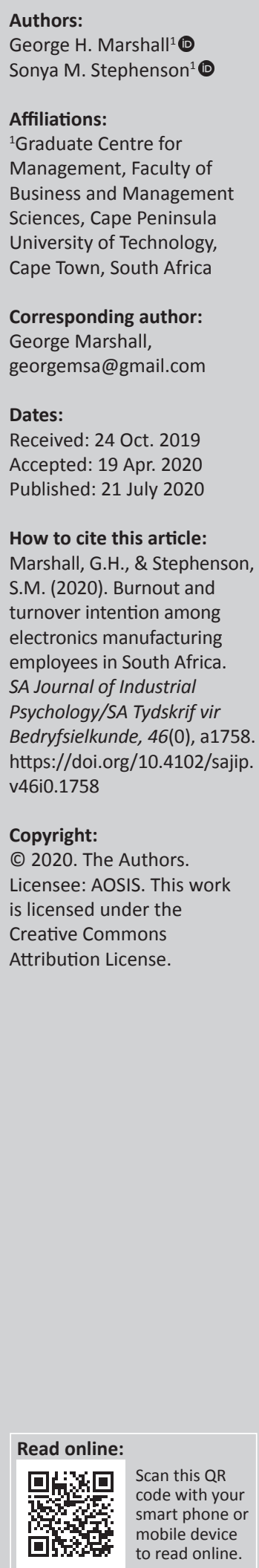

Orientation: Although previous research found evidence that burnout is associated with turnover intention, few studies explore this phenomenon among electronics manufacturing employees in South Africa.

Research purpose: To investigate the relationship between burnout and turnover intention among electronics manufacturing employees.

Motivation for the study: The study explored the relationship between burnout and turnover intention in order to propose interventions that can reduce burnout and turnover intention in electronics manufacturing companies.

Research approach/design and method: The study employed a cross-sectional quantitative research methodology: a self-administered structured questionnaire, principal component analysis and the Spearman's correlation coefficient. A convenience sample of 133 employees from a selected electronics manufacturing company in South Africa participated in the survey.

Main findings: The development of burnout among electronics manufacturing employees is conceptualised by two dimensions: exhaustion/cynicism and professional efficacy. However, exhaustion/cynicism is the only dimension associated with turnover intention. Exhaustion/cynicism is significantly positively related to job cognitions, job search activities, likelihood of leaving the job and turnover intention. Employees' job functions and satisfaction with stakeholder relationships influence burnout and ultimately turnover intention. Factory workers experienced significantly higher levels of exhaustion/cynicism compared to those performing other functions. Exhaustion/cynicism is significantly negatively associated with supervisor relationships whereas professional efficacy is significantly positively associated.

Practical/managerial implications: The study identified opportunities for electronics manufacturing companies to reduce burnout by developing interventions.

Contribution/value-add: The study makes a number of recommendations to reduce burnout and ultimately increase retention of electronics manufacturing employees.

Keywords: Burnout; turnover intention; relationship between burnout and turnover intention; electronics manufacturing; factory workers.

\section{Introduction}

It is in the interest of all organisations, including electronics manufacturing companies, to identify and understand the causes of burnout in order to mitigate its dysfunctional consequences. Although burnout has numerous causes, this article will only mention some of the antecedents that are affected more directly in the current business environment.

Globalisation and technological innovation have triggered an increase in the number of electronics manufacturing companies that are experiencing major organisational changes such as acquisitions, mergers, downsizings and retrenchments (e.g. Cartwright \& Holmes, 2006, p. 199). The selected company in the present study is an electronics manufacturing plant in South Africa that has a history of downsizings and retrenchments that have contributed to higher job demands due to role overload, role conflict and role ambiguity, and lower job resources due to loss of human capital and social support. Higher job demands and lower job resources may increase the levels of burnout experienced by electronics manufacturing employees $(\mathrm{Hu}$, Schaufeli, \& Taris, 2017, p. 642; Maslach, Schaufeli, \& Leiter, 2001, p. 407; Wang, Huang, \& You, 2016, p. 255). Previous research found evidence that major organisational changes are significant predictors of turnover intention (Holtom, Mitchell, Lee, \& Inderrieden, 2005, p. 345). 
The researcher speculates that employees performing functions directly related to manufacturing are more susceptible to burnout compared to those performing other functions. Two possible explanations are proposed for the high levels of burnout among factory workers. Firstly, employees directly involved in manufacturing functions operate in a controlled factory environment where subordinates and supervisors interact directly on a daily basis. These intense interrelationships between stakeholders can trigger burnout among electronics manufacturing employees (Maslach, Jackson, \& Leiter, 1996, p. 4; Maslach \& Leiter, 2016, p. 103). Although these intense relationships may in some cases lead to work engagement rather than burnout, this is unlikely in the current context, because downsizings and retrenchments at the selected company may contribute to negative outcomes for employee decisionmaking, autonomy and resources (Maslach \& Leiter, 2016). Secondly, satisfaction with supervisor relationships can deteriorate due to the negative consequences of major organisational changes, and ultimately contribute to the burnout of electronics manufacturing employees (Maslach et al., 2001, p. 407; Shah, 2000).

Previous research found evidence that burnout has negative implications for individuals, family and friends, as well as a number of stakeholders in the organisation, including colleagues, subordinates, supervisors and clients (Cordes \& Dougherty, 1993, pp. 639-640; Maslach et al., 1996, p.38). An important consequence of burnout is turnover intention that may ultimately lead to the actual turnover of electronics manufacturing employees (Du Plooy \& Roodt, 2010, p. 11; Mor Barak, Nissly, \& Levin, 2001, p. 652).

The relationship between burnout and turnover intention has been confirmed across different nationalities and occupational groups, for example among public welfare professionals (Lee \& Ashforth, 1993), human service employees (Mor Barak et al., 2001); South African information and communication technology (ICT) employees (Du Plooy \& Roodt, 2010), Chinese automobile manufacturing employees (Lin, Jiang, \& Lam, 2013), Turkish health employees (Elci, Yildiz, \& Karabay, 2018) and Indonesian auditors (Santoso, Sitompul, \& Budiatmanto, 2018). Although previous research has investigated the relationship between burnout and turnover intention across various settings and occupational groups before, to the best of our knowledge, we're the first to address this issue in the electronics manufacturing industry of South Africa.

The aim of this study is to reduce this gap by contributing to the body of knowledge on burnout research of electronics manufacturing employees in South Africa.

\section{Research purpose and objectives}

Voluntary turnover at the selected company has almost doubled from $4.71 \%$ to $8.39 \%$ during the last five years leading up to this study. The respondents in the present study experienced considerable pressures due to the negative outcomes of mergers and downsizings at the selected company which can ultimately lead to burnout. It is proposed that voluntary turnover at the selected company is high because the employees are suffering from burnout. The purpose of this study is to investigate the relationship between burnout and turnover intention among employees at a selected electronics manufacturing company in South Africa.

This research will test the hypothesis that burnout is positively related to turnover intention by answering the following research question: Is there a relationship between burnout and turnover intention at the selected company? If the hypothesis is supported, interventions will be recommended to reduce burnout and turnover intention at the selected company. Implementation of these interventions will increase the productivity and profitability of the selected company by mitigating the negative consequences of burnout and turnover intention.

\section{Literature review Burnout}

Previous research found that burnout is associated with turnover intention not only in the human services and education professions, but also in occupations that are not related to these professions (Visser \& Rothmann, 2008). The development of burnout in occupations other than human services and education is conceptualised as a three-dimensional construct that comprises exhaustion, cynicism and professional efficacy. Exhaustion refers to feelings of physical and emotional fatigue, but without direct reference to people as the source of these feelings. Cynicism is based on negative attitudes toward work rather than personal work relationships and refers to the tendency of employees to distance themselves from work in order to cope with exhausting demands. Professional efficacy refers to self-assessment of employees based on expectations of continued effectiveness at work rather than interaction with people at work.

Maslach and Leiter (2008, p. 498) highlighted the importance of understanding the antecedents of burnout in order to develop interventions that can counter the negative outcomes of burnout. Maslach et al. (2001) categorised the numerous antecedents of burnout as situational and individual factors. Situational factors include job, occupational and organisational characteristics, whereas individual factors include demographic variables, personality characteristics and job attitudes. It appears that burnout is a more social than individual experience, because the association between burnout and situational factors are stronger compared to burnout and individual factors (Maslach et al., 2001, p. 409).

Rapid globalisation and technological innovation are resulting in more electronics manufacturing companies experiencing major organisational changes such as acquisitions, mergers, downsizings and retrenchments.

The electronics manufacturing company in the present study has a history of mergers and acquisitions that contributed to 
downsizings and layoffs. Jennings $(2008$, p. 6) concluded that major organisational changes such as mergers and restructuring not only failed to reach the desired cost reductions, but also contributed directly to burnout of employees. Furthermore, major organisational changes may have an indirect effect on the burnout of employees by influencing their job attitudes such as career progress, expectations, autonomy, feedback and decision-making (Cordes \& Dougherty, 1993, pp. 636-637; Maslach et al., 2001, p. 407).

Retrenchments and downsizings at electronics manufacturing companies may also have an indirect influence on the burnout of employees by affecting their job demands and resources. Employees that remain after a downsizing may experience higher job demands, because they may be expected to perform the additional work tasks of those that left the company (Maslach \& Goldberg, 1998, p. 65). Furthermore, when layoffs directly affect supervisors or managers, it may have negative implications for a number of variables that are related to the job resources of employees, for example social support (Elci et al., 2018, p. 57; Kim, 2016, p. 21), role ambiguity and role conflict (Maslach et al., 2001, p. 407). Previous research found evidence that higher job demands and lower job resources are significant predictors of burnout for employees (Maslach \& Goldberg, 1998, p. 65; Maslach et al., 2001, p. 407; Wang et al., 2016, p. 255).

Mergers and acquisitions may have negative outcomes for job attitudes, such as career progress and expectations, which may encourage employees to change their perceptions of organisational obligations and contributions (Bellou, 2006, p. 78). Employees may view the outcomes of a merger as an escalation in violation of the psychological contract, because most of the previously agreed conditions may change after such an event, including contract, colleagues and reporting structures (Linde \& Schalk, 2006, p. 487). The psychological contract is the employee's belief that the employer will fulfil perceived promises based on mutual exchange (Maslach et al., 2001, p. 409; Rousseau, 1995). Previous research found evidence that violation of the psychological contract between the employee and employer is related to burnout (Pines, 2002, p. 13; Schaufeli \& Greenglass, 2001, p. 503).

Previous research found evidence that burnout experienced by an individual may have negative outcomes for a variety of stakeholders, including employers, colleagues, clients, family and friends (Cordes \& Dougherty, 1993, pp. 639-640). Schaufeli (2003, pp. 8-9) categorised the numerous consequences of burnout as ill-health outcomes, negative job attitudes and impaired organisational behaviour. Turnover intention is the dependent variable in the present study and a key impaired organisational outcome of burnout. Previous research found evidence that burnout and its individual components are significantly related to turnover intention (Du Plooy \& Roodt, 2010, p. 11; Han, Bonn, \& Cho, 2016; Lin et al., 2013).

\section{Turnover intention}

Previous research on turnover focused predominantly on job satisfaction and demographic variables as determinants of turnover intention (Martin, 1979, p. 313), but subsequent studies were expanded to include new approaches such as the unfolding model of voluntary turnover (Lee \& Mitchell, 1994; Morrell, Loan-Clarke, \& Wilkinson, 2001; Rouse, 2001). Some studies used turnover intention as a substitute for actual turnover due to the significant relationship between the variables (Hailu, Sisay, \& Negash, 2016, p. 195; Mor Barak et al., 2001, p. 652). Furthermore, turnover intention is more suited to a cross-sectional methodological approach compared to actual turnover and therefore avoids the logistical challenges of longitudinal studies (Maslach et al., 1996, p. 34; Mor Barak et al., 2001, p. 630). Turnover intention is described as an individual's estimated probability to quit in the near future (Brough \& Frame, 2004, p. 8).

Electronics manufacturing companies have vested interest in the prediction of turnover intention, because it is a signal of quitting (Weisberg, 1994, p. 4) and may indicate the need for interventions to reduce actual turnover. Mor Barak et al. (2001, p. 633) categorise the antecedents of intention to leave and turnover as demographic characteristics, professional perceptions and organisational conditions. Burnout is the independent variable in the present study and represents a professional perception that predicts turnover intention. Previous research found evidence that burnout and its individual components are significantly related to turnover intention (Goddard \& Goddard, 2006; Lin et al., 2013; Mor Barak et al., 2001, pp. 652-653).

According to Holtom et al. (2005, p. 345), employees view mergers and acquisitions as shock events that can contribute to higher levels of turnover intention and actual turnover. The major predictors of turnover are more strongly related to job and organisational factors rather than personal and workfamily variables (Mor Barak et al., 2001, p. 655). Managers and policymakers can influence the job and organisational variables of employees directly and are therefore instrumental in reducing turnover intention and actual turnover.

Studies on the consequences of turnover intention other than actual turnover have been limited (Krishnan \& Singh, 2010, p. 423). Turnover intention is the strongest predictor of actual turnover (Mor Barak et al., 2001, p. 652) and can ultimately lead to positive or negative costs for the organisation, for example increased performance or operational disruption (Staw, 1980). According to Bowen (1982, p. 210), absenteeism, being fired and changes in job performance are unintended consequences of turnover intention. Bowen proposes further research on the other unintended consequences of turnover intention such as alcoholism, heightened search activity and decreased self-confidence.

\section{Relationship between burnout and turnover intention}

Electronics manufacturing employees are normally employed in occupations that are not associated with human services or education, for example engineering managers, general office staff, production workers, technicians and engineers. 
According to Mor Barak et al. (2001, p. 653), burnout is one of the best predictors of turnover in the human service professions, while job performance and absenteeism are important antecedents of turnover in most other occupations. However, many studies found evidence that burnout is not only related to turnover intention in the human service professions (Scanlan \& Still, 2013), but also in other occupations that are not related to these professions (Chan, Wan, \& Kuok, 2015; DuPlooy \& Roodt, 2010; Kartono \& Hilmiana, 2018; Kaatz, French, \& Prentiss-Cooper, 1999, pp. 169-170; Santoso et al., 2018).

Previous research that supports the three-dimensional association between burnout and turnover intention across different job functions, settings and countries is discussed next. Kaatz et al. (1999, pp. 169-170) found evidence that burnout is related to the turnover cognitions of city managers. The findings of the study demonstrated that managers experiencing high levels of burnout are significantly more likely to actively think about quitting than those with low levels of burnout. In a study of casino employees, Chan et al. (2015, p. 360) found that all three components of burnout are significantly related to turnover intention. The results of the study demonstrated that emotional exhaustion and depersonalisation are significantly positively related to turnover intention, while personal accomplishment is significantly negatively related to the outcome variable. Many other studies confirmed the relationship between burnout and turnover intention across different job functions and countries, for example South African ICT employees (DuPlooy \& Roodt, 2010), Indonesian banking employees (Kartono \& Hilmiana, 2018) and Indonesian auditors (Santoso et al., 2018).

Although previous research concluded that all the components of burnout contribute to the prediction of turnover intention, some studies found that the exhaustion dimension is the predominant component that predicts the outcome variable (Cropanzano, Rupp, \& Byrne, 2003, p. 166). Moore (2000) found that American information technology professionals experiencing high levels of exhaustion reported higher levels of turnover intention compared to those with low levels of exhaustion. Similarly, Rothmann and Joubert (2007) demonstrated that exhaustion and cynicism are associated with the organisational commitment of South African mine workers and ultimately their turnover intentions. In a study of Chinese automobile manufacturing employees, Lin et al. (2013, p. 462) found that emotional exhaustion is associated with turnover intention. The findings demonstrated that managers experiencing high levels of emotional exhaustion report higher levels of turnover intention compared to those with low levels of emotional exhaustion. Furthermore, Lee and Eissenstat (2018) found that corporate technology employees experiencing high levels of emotional exhaustion, report significantly higher levels of turnover intention compared to those with low levels of emotional exhaustion.

Previous research on the causes and consequences of burnout and its association with turnover intention has focused predominantly on the human service and education professions. Although this research has been expanded over the last 20 years to include occupations other than human services and education, very few studies have been conducted on electronics manufacturing companies. The present study reduces this gap in research by investigating the antecedents and outcomes of burnout, as well as its relationship to turnover intention in electronics manufacturing companies in South Africa.

\section{Research design Research approach}

The present study adopted a cross-sectional quantitative approach to measure the levels of burnout and turnover intention experienced by the respondents. Applicable methods were selected to collate and interpret the research data in order to answer the following research question: Is there a relationship between burnout and turnover intention at the selected company? The present study employed a non-probability sampling methodology and used a self-administered survey to collect the research data among employees in a selected electronics manufacturing company in South Africa.

\section{Research method}

Research participants

The selected company employed 283 employees performing various occupational functions. Fifty-three of the employees were excluded from the study for various reasons, for example employees permanently located off site or pilot study participants. A total of 230 employees were invited to participate in the survey and 133 completed questionnaires were returned after the completion date, resulting in a response rate of $58 \%$.

According to Table 1, the respondents in the present study were relatively young with the majority of them aged 40 years or younger $(M=37.22, \mathrm{SD}=8.87)$. The respondents were predominantly female $(57.3 \%)$ and more than half of them were married $(57.7 \%)$ with a further $8.5 \%$ cohabitating with a partner. More than two-thirds of the respondents (70.5\%) had between one and three children. The majority of the respondents had school level educational qualifications while only $2.4 \%$ of them had postgraduate qualifications. More than half of the respondents $(52.4 \%)$ reported their job tenure as 10 years or longer $(M=9.7, \mathrm{SD}=6.5)$ and the overwhelming majority $(96.2 \%)$ was employed by the selected company on a permanent basis. Almost two-thirds of the respondents $(66.4 \%)$ were employed in the production or production support departments. Around one-third (33.6\%) of the respondents performed non-factory functions and were not directly involved in manufacturing activities.

\section{Measuring instruments}

\section{Maslach Burnout Inventory - General Survey}

The levels of burnout experienced by respondents in the present study were measured using the Maslach Burnout 
TABLE 1: Characteristics of the respondents.

\begin{tabular}{|c|c|c|}
\hline Variable & Category & Respondents (\%) \\
\hline \multirow[t]{2}{*}{ Age $(N=119)$} & $21-40$ years & 63.0 \\
\hline & $>40$ years & 37.0 \\
\hline \multirow{2}{*}{$\begin{array}{l}\text { Gender } \\
(N=131)\end{array}$} & Male & 42.7 \\
\hline & Female & 57.3 \\
\hline \multirow{6}{*}{$\begin{array}{l}\text { Marital status } \\
(N=130)\end{array}$} & Married & 57.7 \\
\hline & Unmarried, cohabitating & 8.5 \\
\hline & Divorced & 4.6 \\
\hline & Separated & 2.3 \\
\hline & Widowed & 2.3 \\
\hline & Single & 24.6 \\
\hline \multirow{6}{*}{$\begin{array}{l}\text { Number of children } \\
(N=115)\end{array}$} & 0 & 27.8 \\
\hline & 1 & 20.9 \\
\hline & 2 & 28.7 \\
\hline & 3 & 20.9 \\
\hline & 4 & 0.9 \\
\hline & 5 & 0.9 \\
\hline \multirow{7}{*}{$\begin{array}{l}\text { Education level } \\
(N=127)\end{array}$} & Grade 11 & 37.0 \\
\hline & Grade 12 & 33.1 \\
\hline & Post School Diploma & 8.7 \\
\hline & National Diploma & 16.5 \\
\hline & Bachelor's Degree & 2.4 \\
\hline & Honour's Degree & 0.8 \\
\hline & Master's Degree & 1.6 \\
\hline \multirow{2}{*}{$\begin{array}{l}\text { Job tenure } \\
(N=124)\end{array}$} & $<10$ years & 47.6 \\
\hline & $\geq 10$ years & 52.4 \\
\hline \multirow{2}{*}{$\begin{array}{l}\text { Employment type } \\
(N=132)\end{array}$} & Permanent & 96.2 \\
\hline & Temporary & 3.8 \\
\hline \multirow{12}{*}{$\begin{array}{l}\text { Department } \\
(N=131)\end{array}$} & Production & 60.3 \\
\hline & Production support & 6.1 \\
\hline & Supply chain & 6.1 \\
\hline & Stores & 8.4 \\
\hline & Quality \& reliability & 5.3 \\
\hline & Service & 1.5 \\
\hline & Human resources & 0.8 \\
\hline & Information technology & 1.5 \\
\hline & Finance & 2.3 \\
\hline & Despatch \& logistics & 3.8 \\
\hline & Maintenance & 1.5 \\
\hline & Other & 2.3 \\
\hline \multirow{2}{*}{$\begin{array}{l}\text { Factory or non-factory } \\
(N=131)\end{array}$} & Factory & 66.4 \\
\hline & Non-factory & 33.6 \\
\hline
\end{tabular}

Inventory - General Survey (MBI-GS) instrument (Maslach et al., 1996). Unlike the original MBI, the MBI-GS was designed for occupations other than human service and education professions and assesses the three components of burnout, namely exhaustion, cynicism and professional efficacy. The MBI-GS measures burnout using 16 items on a seven-point scale ranging from 'never' to 'daily'. A factor analysis was conducted to determine if the factor structure of the MBI-GS in the present study corresponds to the threedimensional solution proposed by Maslach et al. (1996, p. 20). The factor analysis produced two factors, namely exhaustion/ cynicism and professional efficacy. All 16 items were included in the two factors and the internal consistency of the MBI-GS subscales was sufficient $(\alpha>0.7)$.

In the absence of clinically validated thresholds for burnout in the South African context, the present study derived cutoff points for the research sample by arbitrarily dividing the subscale scores into tertiles as recommended by Maslach et al. (1996, p. 5). Subscale scores are considered high in the upper third of the distribution, average in the middle third and low if in the lower third. Furthermore, the subscale scores were considered separately and not combined into a single total score. Low levels of exhaustion/cynicism combined with high levels of professional efficacy reflect low burnout. Moderate levels of exhaustion/cynicism combined with moderate levels of professional efficacy reflect moderate burnout. High levels of exhaustion/cynicism combined with low levels of professional efficacy reflect high burnout.

\section{Turnover intention survey}

The levels of turnover intention experienced by respondents in the present study were measured using a modified version of the three-item instrument that was used by Brough and Frame (2004, p. 10). Turnover intention levels were measured using three items on a five-point response scale. The response scales for two items ranged from 'not at all' to 'a great deal' and the third item from 'very unlikely' to 'very likely'. The turnover intention scale demonstrated acceptable inter-item correlations and good internal consistency $(\alpha>0.800)$. As was the case for burnout, no clinically validated thresholds exist for the South African context and numerical cut-off points were derived for the turnover intention scale by arbitrarily dividing the ordered distribution into equal tertiles (Maslach et al., 1996, p. 5).

\section{Pilot study}

In order to improve the likelihood of success, the selfadministered questionnaire was completed by a convenience sample of four pilot participants. The respondents included one English-speaking female statistician, one Englishspeaking female human resources manager and two Afrikaans-speaking male worker union representatives. All recommendations from respondents were included in the final version of the questionnaire and all pilot participants were excluded from the main study.

\section{Research procedure and ethical consideration}

The researcher sent a written request to conduct research to the management of the selected electronics manufacturing company. After receiving written management approval, the researcher distributed pen-and-paper copies of the selfadministered questionnaire to potential participants in the selected company. The questionnaire was accompanied by a cover letter that outlined the relevant details of the survey, such as purpose, duration, completion date, confidentiality assurances and contact information.

In accordance with company policies, the human resources manager of the selected company sent three emails to potential respondents to encourage participation in the survey and to provide further details. All completed questionnaires were returned in the sealed envelopes that were distributed with the questionnaires. The researcher captured the responses from participants in a Statistical 
Package for Social Science (SPSS) data file for data analysis purposes.

All research activities were delayed until the researcher received ethics clearance from the university and written approval from the selected company to conduct the study. The present study complied with all the requirements of the selected company, including minimum work disruption, non-disclosure of company name and confidentiality of company documents. Names of participants were not recorded during the survey and therefore satisfied the requirements for privacy, anonymity and confidentiality. The participants of the study were provided with all the required information to complete the survey and data collected was only used for research purposes.

\section{Statistical analysis}

SPSS version 23.0 was used to analyse the research data and statistics techniques were selected based on the hypothesis, research design and type of data used in the present study. Frequency distributions and descriptive statistics were generated to provide meaningful summaries of the quantitative data.

Principal component analysis using varimax rotation with Kaiser normalisation was used to compare the factor structure in the present study with the commonly accepted three-factor structure of the MBI-GS (Maslach et al., 1996, p. 20). None of the items loaded on multiple factors in the final model and only factor loadings that reached the threshold $r \geq 0.3$ were retained (Torkzadeh \& Dhillon, 2002, p. 192). As recommended by Nunnally and Bernstein (1994), the Cronbach's alpha coefficient was greater than 0.7 and indicated adequate internal consistency for the MBI-GS subscales.

Independent samples $t$-tests, one-way analysis of variance (ANOVA) and Spearman's correlation tests were used to evaluate the relationships between the burnout subscales and demographic cohorts of interest. Interpretation of the results was based on a significance threshold of 0.05 for the Levene's test (Sig.), t-test (Sig. two-tailed) and one-way ANOVA. Where the one-way ANOVA revealed statistically significant differences between the group means, post hoc tests using the Bonferroni correction method were used to identify the specific groups that were affected.

Some of the variables in the present study were evaluated on ordinal scales and the constructs did not meet the requirements for normality. Consequently, the Spearman's correlation coefficient was used in the present study rather than the Pearson coefficient. The Spearman's correlation coefficient was used to assess the strength and direction of the relationships between the burnout dimensions and important stakeholder relationships and turnover intention. Correlations were interpreted as practically significant for thresholds $r \geq 0.25$ and $p<0.05$.

\section{Results}

\section{Burnout and turnover intention cut-off points}

Table 2 shows the numerical cut-off points that were derived by arbitrarily dividing the burnout and turnover intention subscale scores into equal tertiles (Maslach et al., 1996, p. 5). According to this categorisation, the respondents in the present study experience moderate levels of exhaustion/ cynicism $($ mean $[M]=2.15$, standard deviation $[\mathrm{SD}]=1.49)$ and professional efficacy $(M=4.84, \mathrm{SD}=1.16)$ that can be categorised as moderate burnout. However, the respondents in the upper exhaustion/cynicism tertile experience high levels of exhaustion/cynicism $(M=3.92, \mathrm{SD}=0.85)$ and low levels of professional efficacy $(M=4.75, \mathrm{SD}=1.16)$ that can be categorised as high burnout. Furthermore, the overall sample experiences moderate levels of turnover intention $(M=2.54$, $\mathrm{SD}=1.14$ ), while the respondents in the upper exhaustion/ cynicism tertile experience high levels of turnover intention $(M=3.39, \mathrm{SD}=1.07)$.

\section{Relationship between burnout and demographic variables}

According to the results in Table 3, the mean scores of exhaustion/cynicism are statistically significantly different for factory and non-factory cohorts $(F=10.316, p=0.002)$. The results suggest that factory employees $(M=2.41$, $\mathrm{SD}=1.56)$ experience significantly higher levels of exhaustion/cynicism compared to non-factory employees $(M=1.57, \mathrm{SD}=1.04)$. However, factory and non-factory cohorts do not contribute to statistically significant differences in the mean scores of professional efficacy $(F=$ $2.412, p=0.123)$. The $p$-value is above the significance level $(p<0.05)$ and discrepancies between group means of the

\begin{tabular}{|c|c|c|c|c|c|}
\hline Tertiles & $N$ & Minimum & Maximum & Mean & Standard deviation \\
\hline \multicolumn{6}{|c|}{ Exhaustion/cynicism } \\
\hline Lower & 41 & 0.00 & 1.00 & 0.56 & 0.29 \\
\hline Middle & 42 & 1.10 & 2.70 & 1.96 & 0.43 \\
\hline Upper & 41 & 2.90 & 6.00 & 3.92 & 0.85 \\
\hline \multicolumn{6}{|c|}{ Professional efficacy } \\
\hline Lower & 41 & 0.00 & 4.83 & 3.58 & 1.14 \\
\hline Middle & 42 & 4.83 & 5.50 & 5.10 & 0.20 \\
\hline Upper & 41 & 5.50 & 6.00 & 5.85 & 0.17 \\
\hline \multicolumn{6}{|c|}{ Turnover intention } \\
\hline Lower & 41 & 1.00 & 2.00 & 1.30 & 0.31 \\
\hline Middle & 41 & 2.00 & 3.00 & 2.43 & 0.33 \\
\hline Upper & 41 & 3.00 & 5.00 & 3.88 & 0.58 \\
\hline
\end{tabular}

TABLE 3: Factory or non-factory cohorts (analysis of variance).

\begin{tabular}{|c|c|c|c|c|c|}
\hline Variable & $N$ & Mean & Standard deviation & $F$ & Significance \\
\hline \multicolumn{6}{|c|}{ Exhaustion/cynicism } \\
\hline Factory & 86 & 2.41 & 1.56 & 10.316 & 0.002 \\
\hline Non-factory & 44 & 1.57 & 1.04 & - & - \\
\hline Total & 130 & 2.12 & 1.46 & - & - \\
\hline \multicolumn{6}{|c|}{ Professional efficacy } \\
\hline Factory & 85 & 4.76 & 1.25 & 2.412 & 0.123 \\
\hline Non-factory & 44 & 5.09 & 0.92 & - & - \\
\hline Total & 129 & 4.87 & 1.16 & - & - \\
\hline
\end{tabular}


factory and non-factory cohorts are likely due to chance and not related to significant differences between cohorts.

\section{Relationship between burnout and other variables of interest}

According to the results in Table 4, Spearman's rho revealed weak negative statistically significant relationships between exhaustion/cynicism and supervisor $\left(p<0.001, r_{\mathrm{s}}=-0.347\right)$, as well as subordinate relationships ( $\left.p=0.001, r_{\mathrm{s}}=-0.296\right)$. This suggests that the levels of exhaustion/cynicism experienced by the respondents increase as relationships with supervisors and subordinates deteriorate. Furthermore, the results demonstrated a weak positive statistically significant relationship between professional efficacy and supervisor relationships ( $\left.p=0.001, r_{\mathrm{s}}=0.301\right)$. This suggests that the levels of professional efficacy experienced by respondents increase as relationships with supervisors improve. However, the results did not reveal any statistically significant or practically relevant relationships between burnout and co-worker relationships.

\section{Relationship between burnout and turnover intention}

The relationship between burnout and turnover intention was evaluated by means of one-way ANOVA, post hoc Bonferroni and Spearman's correlation tests. According to the results in Table 5, the one-way ANOVA revealed statistically significant differences in the mean scores of turnover intention for the different exhaustion/cynicism tertiles $(F=25.360, p<0.001)$, but not for the professional

TABLE 4: Burnout and stakeholder relationships.

\begin{tabular}{|c|c|c|c|c|c|}
\hline \multicolumn{2}{|c|}{ Spearman's correlation coefficient } & \multicolumn{2}{|c|}{ Exhaustion/cynicism } & \multicolumn{2}{|c|}{ Professional efficacy } \\
\hline Variable & $N$ & $p \dagger$ & $r_{s}$ & $p \dagger$ & $r_{s}$ \\
\hline Co-workers & 120 & 0.195 & -0.119 & 0.276 & 0.100 \\
\hline Supervisors & 120 & 0.000 & -0.347 & 0.001 & 0.301 \\
\hline Subordinates & 117 & 0.001 & -0.296 & 0.065 & 0.171 \\
\hline
\end{tabular}

Note: $p$-value (two-tailed) $\leq 0.05$ statistically significant; $r_{s} \geq 0.25$ practically relevant.

\begin{tabular}{lccccc}
\hline TABLE 5: Burnout and turnover intention (analysis of variance). \\
\hline Tertile & $\boldsymbol{N}$ & $\begin{array}{c}\text { Mean } \\
\text { (turnover intention) }\end{array}$ & $\begin{array}{c}\text { Standard } \\
\text { deviation }\end{array}$ & $\boldsymbol{F}$ & Significance \\
\hline Exhaustion/cynicism & & & & & \\
Low & 41 & 1.91 & 0.94 & 25.360 & 0.000 \\
Moderate & 42 & 2.33 & 0.87 & - & - \\
High & 40 & 3.39 & 1.07 & - & - \\
Professional efficacy & & & & & \\
Low & 41 & 2.57 & 1.22 & 0.139 & 0.871 \\
Moderate & 42 & 2.58 & 1.08 & - & - \\
High & 40 & 2.46 & 1.13 & - & - \\
\hline
\end{tabular}

efficacy tertiles $(F=0.139, p=0.871)$. The $p$-value is above the significance level $(p<0.05)$ and discrepancies between group means of the professional efficacy tertiles are likely due to chance and not related to significant differences between cohorts.

Post hoc tests using the Bonferroni correction method were conducted to control the type 1 error rate and determine which pairs of the exhaustion/cynicism tertiles revealed significant differences in turnover intention. Bonferroni post hoc tests were not required for the professional efficacy tertiles, because the ANOVA revealed no statistically significant differences between the group means. The post hoc test results in Table 6 were obtained from SPSS and represent pair-wise Bonferroni-adjusted $p$-values that were directly compared to the 0.05 significance level. According to the results in Table 6, statistically significant differences in turnover intention are revealed between the low and high (mean difference $=1.4811, p<0.001$ ) as well as the moderate and high (mean difference $=1.0583, p<0.001$ ) exhaustion/cynicism tertiles. This suggests that respondents in the upper tertile $(M=3.39, \mathrm{SD}=1.07)$ of the exhaustion/cynicism subscale experience significantly higher levels of turnover intention compared to those in the middle $(M=2.33, \mathrm{SD}=0.87)$ and lower tertiles $(M=1.91$, $\mathrm{SD}=0.94)$. According to the results, no statistically significant differences in turnover intention are experienced by respondents in the lower and middle tertiles of the exhaustion/cynicism subscale (mean difference $=0.4227$, $p=0.143)$.

According to the results in Table 7, Spearman's rho revealed a moderate positive statistically significant relationship between exhaustion/cynicism and turnover intention $\left(p<0.001, r_{\mathrm{s}}=0.542\right)$. This suggests that the turnover intention of the respondents increases as the levels of exhaustion/ cynicism escalate.

TABLE 7: Relationship between burnout and turnover intention.

\begin{tabular}{lcccccc}
\hline $\begin{array}{l}\text { Spearman's correlations } \\
(N=123)\end{array}$ & \multicolumn{2}{c}{$\begin{array}{c}\text { Exhaustion/ } \\
\text { cynicism }\end{array}$} & & \multicolumn{2}{c}{$\begin{array}{c}\text { Professional } \\
\text { efficacy }\end{array}$} \\
\cline { 2 - 3 } & $p$ & $r_{\text {s }}$ & & $p$ & $r_{\text {s }}$ \\
\hline Turnover Intention & 0.000 & 0.542 & & 0.377 & -0.080 \\
$\begin{array}{l}\text { V32: How frequently have you considered } \\
\text { leaving your job in the last } 12 \text { months? }\end{array}$ & 0.000 & 0.566 & 0.298 & -0.095 \\
$\begin{array}{l}\text { V33: How frequently do you actively look for } \\
\text { jobs outside the company? }\end{array}$ & 0.000 & 0.340 & 0.726 & -0.032 \\
$\begin{array}{l}\text { V34: How likely are you to leave your job in } \\
\text { the next } 12 \text { months? }\end{array}$ & 0.000 & 0.452 & 0.286 & -0.097 \\
\hline Note: $p$-value (two-tailed) $\leq 0.05$ statistically significant; $r_{s} \geq 0.25$ & practically relevant.
\end{tabular}

Note: $p$-value (two-tailed) $\leq 0.05$ statistically significant; $r \geq 0.25$ practically relevant.

TABLE 6: Exhaustion/cynicism and turnover intention (Bonferroni correction).

\begin{tabular}{|c|c|c|c|c|c|c|}
\hline \multirow{2}{*}{$\begin{array}{l}\text { Exhaustion/cynicism tertiles: } \\
\text { Multiple comparisons }\end{array}$} & \multirow[t]{2}{*}{ Variable } & \multirow{2}{*}{$\begin{array}{c}\text { Mean } \\
\text { difference }\end{array}$} & \multirow{2}{*}{$\begin{array}{l}\text { Standard } \\
\text { error }\end{array}$} & \multirow{2}{*}{$\begin{array}{l}\text { Significance } \\
\quad(p)\end{array}$} & \multicolumn{2}{|c|}{$95 \%$ confidence level } \\
\hline & & & & & Lower band & Upper band \\
\hline \multirow[t]{2}{*}{ Low } & Moderate & -0.4227 & 0.2115 & 0.143 & -0.9362 & 0.0906 \\
\hline & High & -1.4811 & 0.2140 & 0.000 & -2.0008 & -0.9614 \\
\hline \multirow[t]{2}{*}{ Moderate } & Low & 0.4227 & 0.2115 & 0.143 & -0.0906 & 0.9362 \\
\hline & High & -1.0583 & 0.2128 & 0.000 & -1.5750 & -0.5417 \\
\hline High & Low & 1.4811 & 0.2140 & 0.000 & 0.9614 & 2.0008 \\
\hline
\end{tabular}


Furthermore, the results demonstrated weak to moderate positive statistically significant relationships between exhaustion/cynicism and turnover cognitions (V32, $p<0.001, r_{\mathrm{s}}=0.566$ ), job search activity (V33, $p<0.001$, $\left.r_{\mathrm{s}}=0.340\right)$ and likelihood of leaving the company (V34, $\left.p<0.001, r_{\mathrm{s}}=0.452\right)$. This suggests that turnover cognitions, job search activity and likelihood of leaving the company increase as the levels of exhaustion/cynicism experienced by the respondents escalate. However, no statistically significant or practically relevant relationships were revealed between professional efficacy and turnover intention or any of its items.

\section{Discussion}

\section{Outline of the results}

\section{Burnout and turnover intention levels}

The findings demonstrated that the overall sample in the present study experience moderate levels of burnout and turnover intention. However, the respondents in the upper exhaustion/cynicism tertile or $33 \%$ of the overall sample experience high levels of burnout and turnover intention. This finding is not surprising, because the selected company has a history of mergers and acquisitions that may increase the burnout and turnover intention of employees (ArmstrongStassen, Cameron, Mantler, \& Horsburgh, 2001, p. 158; Jennings, 2008, p. 6).

\section{Relationship between burnout and turnover intention}

Spearman's correlation analysis of the relationship between burnout and turnover intention at the selected company revealed a number of noteworthy findings. According to the results, respondents experiencing higher levels of exhaustion/ cynicism report higher levels of turnover cognitions, job search activity, likelihood of leaving the job and turnover intention. The findings support previous research that found burnout is associated with thoughts about leaving the job (Jackson, Schwab, \& Schuler, 1986, p. 637; Kaatz et al., 1999, p. 169) and turnover intention (Chan et al., 2015), while it contradicts research that found burnout is not related to job search activity and turnover intention (Jackson et al., 1986, p. 637).

Furthermore, the results revealed no statistically significant or practically relevant relationships between professional efficacy and turnover intention or any of its individual items.

Although most previous studies support the commonly accepted three-dimensional relationship between burnout and turnover intention (Chan et al., 2015), the present study found that exhaustion/cynicism is the only burnout dimension that is related to turnover intention. This onedimensional association between burnout and turnover intention is supported by previous research (Cropanzano et al., 2003, p. 166) and therefore not unique to the present study. Previous research that identifies exhaustion as the core component of burnout (Schaufeli \& Van Dierendonck, 1993) while rejecting professional efficacy as a separate dimension of the construct (Demerouti, Bakker, Nachreiner, \& Schaufeli,
2001, p. 500), demonstrates the importance of exhaustion/ cynicism in the present study.

The relationship between the burnout dimensions and turnover intention in the present study may be influenced by major organisational changes and hardiness. Firstly, the selected company has a history of acquisitions and mergers which may contribute to higher levels of burnout (Jennings, 2008, p. 6) and turnover intention (Armstrong-Stassen et al., 2001, p. 158) among employees. Secondly, the absence of an association between professional efficacy and turnover intention in the present study may be due to hardiness (Ndetei et al., 2008, p. 202) as a result of high levels of unemployment and poverty in South Africa. Respondents working in these challenging economic conditions may be encouraged to inflate their professional efficacy scores in order to ensure employment continuity.

The results revealed two noteworthy findings related to demographic variables and stakeholder relationships that may influence the association between exhaustion/cynicism and turnover intention at the selected company. Firstly, factory workers at the selected company experience significantly higher levels of exhaustion/cynicism compared to those performing non-factory functions. This finding suggests that the development of burnout at the selected company is associated with the type of work that employees perform.

The factory and non-factory categories in the present study can be viewed as two departments that include the production and non-production functions. Previous research found evidence that the exhaustion dimension of burnout is associated with the departmental variable (Gaines \& Jermier, 1983 , p. 580). However, this finding must be interpreted with caution, because variables such as job status, nature of work and speciality area may have a confounding influence on the factory/non-factory variable (Cordes \& Dougherty, 1993, p. 632; Gaines \& Jermier, 1983, p. 580). The researcher speculates that non-factory employees perform more enriched work while enjoying higher job status and are therefore less likely to develop burnout. Furthermore, factory employees experience frequent intense interactions with supervisors in a controlled production environment which may contribute to higher levels of burnout. Factory employees at the selected company accounted for an overwhelming majority of the workforce in the present study and may therefore contribute significantly to burnout and ultimately turnover intention at the selected company.

Secondly, the findings suggest that satisfaction with supervisor and subordinate relationships deteriorates as the levels of exhaustion/cynicism experienced by the respondents escalate. This finding is important in the selected company where factory workers experience high levels of exhaustion/cynicism and intense interactions with supervisors on a daily basis. Furthermore, the results suggest that satisfaction with supervisor relationships improves as 
the levels of professional efficacy experienced by respondents escalate.

High levels of exhaustion/cynicism combined with low levels of professional efficacy reflect high burnout and thus low satisfaction with supervisor relationships. Previous studies found evidence that social support is associated with burnout (Maslach et al., 2001, p. 407) and organisational downsizing (Shah, 2000). These findings suggest that the development of burnout at the selected company is associated with supervisor and subordinate, but not co-worker, relationships.

The research hypothesis in the present study proposes that burnout is positively related to turnover intention and, as a result, employees experiencing high burnout will be more likely to leave the selected company compared to those with low burnout. According to the results, exhaustion/cynicism is the only burnout dimension that is positively related to turnover intention in the present study. The results suggest that employees experiencing higher levels of exhaustion/ cynicism have greater intention to leave the selected company compared to those experiencing lower levels of exhaustion/ cynicism. The hypothesis in the present study is only partially supported, because the relationship between burnout and turnover intention is based on a single burnout dimension, rather than all three.

\section{Practical implications}

The present study has a number of practical implications for electronics manufacturing companies that wish to reduce burnout and turnover intention among their employees. Firstly, employees performing functions that are directly associated with manufacturing, experience significantly higher levels of exhaustion/cynicism compared to those performing other functions. Secondly, the levels of exhaustion/cynicism reported by electronics manufacturing employees are significantly negatively related to satisfaction with subordinate and supervisor relationships. On the other hand, the levels of professional efficacy reported by electronics manufacturing employees are significantly positively related to satisfaction with supervisor relationships. Thirdly, the levels of exhaustion/cynicism reported by electronics manufacturing employees are significantly positively related to turnover cognitions, job search activity, likelihood of leaving the job and turnover intention. Frequent intense interaction between subordinates and supervisors in electronics manufacturing companies and the influence of major organisational changes on these interrelationships provide plausible explanations for these findings.

Electronics manufacturing companies that wish to reduce burnout and turnover intention among employees may introduce a number of practical interventions. Managers in electronics manufacturing companies are instrumental in the intervention process, because many of the variables that influence burnout and turnover intention are under their direct control. Change management training for managers in electronics manufacturing companies may contribute to lower burnout and higher acceptance of major organisational change (Leiter \& Harvie, 1997, 1998). In order to mitigate the negative outcomes of burnout and turnover intention, electronics manufacturing companies must provide employees with the necessary social support and resources to deal with major organisational changes and intense stakeholder relationships (Lin et al., 2013, p. 465). Furthermore, electronics manufacturing companies can organise factory workers into teams administered by team leaders (Blankertz \& Robinson, 1997, pp. 528-529) and encourage team building activities to mitigate the detrimental outcomes of burnout and turnover intention.

\section{Limitations and recommendations}

The present study determined that burnout is related to turnover intention, but could not determine the direction of causality between the variables. In order to establish whether burnout predicts turnover intention, future research must be based on controlled studies that use multiple regression analysis to test the relationship between the variables. The present study used non-probability convenience sampling techniques that cannot produce justifiable generalisations unless additional research is conducted (Seeletse, 2001, p. 505). This suggests that the findings of the present study are representative of the targeted population, but cannot be generalised to other populations. Future studies must use probability sampling techniques to ensure that the findings are representative of the targeted population and generalisable to other populations. The present research used a cross-sectional quantitative methodology to assess the relationship between burnout and turnover intention at the selected company. Future studies should include longitudinal qualitative techniques that produce correlation patterns of variables over time and results that can be compared to the quantitative responses of participants.

The present research adopted the 'healthy worker' approach due to the limited scope and feasibility of the study (Schaufeli, 2003 , p. 5) and therefore focused only on healthy employees and ignored those who were absent during the survey. In order to gain a more accurate reflection of the level of burnout in electronics manufacturing companies, future studies should include healthy workers, as well as those who were absent, ill or retrenched.

Ethnicity as an antecedent of burnout was excluded from the present study due to concerns that ethnic classifications in the survey may intensify racial sensitivities and ultimately lead to fewer responses from participants. In order to gain a better understanding of the influence of ethnicity on burnout, future studies should investigate the association between the variables in the multi-ethnic South African business environment. Furthermore, future research should assess how stakeholder relationships, hardiness and major organisational changes influence the relationship between burnout and turnover intention in electronics manufacturing companies. 
Notwithstanding the recommendations by Maslach et al. (1996, p. 7), the MBI-GS was used as a self-administered instrument in the present study and supervisors were directly involved in the distribution of questionnaires. Future studies should use trained examiners that are not direct supervisors of the respondents to administer the MBI-GS.

\section{Conclusion}

The present research demonstrated that the development of burnout among electronics manufacturing employees is conceptualised by two dimensions, namely exhaustion/ cynicism and professional efficacy.

According to the results, electronics manufacturing employees who experienced high burnout reported significantly higher levels of turnover intention compared to those who experienced low burnout. The findings showed that exhaustion/cynicism is the only burnout dimension that is related to turnover cognitions, job search activity, likelihood of leaving the job and turnover intention. According to the results, the type of work that the respondents perform and their satisfaction with stakeholder relationships are intervening variables that may influence the levels of burnout and ultimately turnover intention.

The present study identified the job function of employees as an indicator for the development of burnout in electronics manufacturing companies. Factory workers or those performing functions that are directly related to manufacturing, experience significantly higher levels of exhaustion/cynicism compared to employees performing other functions. According to the results, satisfaction with stakeholder relationships is another variable that may contribute to the development of burnout and turnover intention in electronics manufacturing companies. The results showed that electronics manufacturing employees who are less satisfied with subordinate or supervisor relationships, report higher levels of exhaustion/cynicism compared to those who are more satisfied with these relationships. Furthermore, the results revealed that electronics manufacturing employees who are less satisfied with supervisor relationships report lower levels of professional efficacy compared to those who are more satisfied with these relationships.

The present research proposes a number of interventions to mitigate the harmful effects of burnout and turnover intention in electronics manufacturing companies. In order to maximise the impact of interventions in electronics manufacturing companies, wellness programmes must be targeted at four key cohorts, namely factory workers, managers, supervisors and subordinates.

\section{Acknowledgements}

The employees of the selected company for their participation in the study.

\section{Competing interests}

The authors have declared that no competing interests exist.

\section{Authors' contributions}

G.H.M. is the major contributor to this research, including the research design, survey and writing of the manuscript. S.M.S., as supervisor of the research study, has contributed intellectual and scholarly perspectives to broaden and enrich the study.

\section{Funding Information}

This research received no specific grant from any funding agency in the public, commercial, or not-for-profit sectors.

\section{Data availability statement}

Data collected from the survey is stored by the researcher in Cape Town, South Africa.

\section{Disclaimer}

The views and opinions expressed in this article are those of the authors and do not necessarily reflect the official policy or position of any affiliated agency of the authors.

\section{References}

Armstrong-Stassen, M., Cameron, S., Mantler, J., \& Horsburgh, M. (2001). The impact of hospital amalgamation on the job attitudes of nurses. Canadian Journal of Administrative Sciences, 18(3), 149-162. https://doi.org/10.1111/j.1936-4490. 2001.tb00252.x

Bellou, V. (2006). Psychological contract assessment after a major organizational change: The case of mergers and acquisitions. Employee Relations, 29(1), 68-88. https://doi.org/10.1108/01425450710714487

Blankertz, L., \& Robinson, S. (1997). Turnover intentions of community mental health workers in psychosocial rehabilitation services. Community Mental Health Journal, 33(6), 517-529. https://doi.org/10.1023/a:1025000703487

Bowen, D.E. (1982). Some unintended consequences of intention to quit. Academy of Management Review, 7(2), 205-211. https://doi.org/10.5465/amr.1982. 4285563

Brough, P., \& Frame, R. (2004). Predicting police job satisfaction and turnover intentions: The role of social support and police organisational variables. New Zealand Journal of Psychology, 33(1), 8-16. http://hdl.handle.net/10072/5656

Cartwright, S., \& Holmes, N. (2006). The meaning of work: The challenge of regaining employee engagement and reducing cynicism. Human Resource Management Review, 16(2), 199-208. https://doi.org/10.1016/j.hrmr.2006.03.012

Chan, S., Wan, Y., \& Kuok, O. (2015). Relationships among burnout, job satisfaction and turnover of casino employees in Macau. Journal of Hospitality Marketing \& Management, 24(4), 345-374. https://doi.org/10.1080/19368623.2014.911712

Cordes, C.L., \& Dougherty, T.W. (1993). A review and an integration of research on job burnout. The Academy of Management Review, 18(4), 621-656. https://doi. org $/ 10.2307 / 258593$

Cropanzano R Rupp, D \& Byrne, Z (2003). The relationship of emotional exhaustion to work attitudes, job performance, and organizational citizenship behaviors. Journal of Applied Psychology, 88(1), 160-169. https://doi.org/10.1037/00219010.88.1.160

Demerouti, E., Bakker, A., Nachreiner, F., \& Schaufeli, W. (2001). The job demandsresources model of burnout. Journal of Applied Psychology, 86(3), 499-512. https://doi.org/10.1037/0021-9010.86.3.499

Du Plooy, J., \& Roodt, G. (2010). Work engagement, burnout and related constructs as predictors of turnover intentions. SA Journal of Industrial Psychology, 36(1), 1-13. https://doi.org/10.4102/sajip.v36i1.910

Elci, M., Yildiz, B., \& Karabay, M.E. (2018). How burnout affects turnover intention? The conditional effects of subjective vitality and supervisor support. International Journal of Organizational Leadership, 71, 47-60. https://doi.org/10.33844/ ijol.2018.60233

Gaines, J., \& Jermier, J. (1983). Emotional exhaustion in a high stress organization Academy of Management Journal, 26(4), 567-586. https://doi.org/10.2307/ 255907 
Goddard, R., \& Goddard, M. (2006). Beginning teacher burnout in Queensland schools: Associations with serious intentions to leave. The Australian Educational schoos: Associations with serious intentions to leave. The Australid
Researcher, 33(2), 61-75. https://doi.org/10.1007/BF03216834

Hailu, T., Sisay, D., \& Negash, E. (2016). Factors affecting turnover intention among health professionals in specialized hospitals - Specifically at Jimma University specialized hospital. European Journal of Business and Management, 8(22) 195-201. https://www.iiste.org/Journals/index.php/EJBM/article/view/32431

Han, S., Bonn, M., \& Cho, M. (2016). The relationship between customer incivility, restaurant frontline service employee burnout and turnover intention. International Journal of Hospitality Management, 52, 97-106. https://doi. org/10.1016/j.jihm.2015.10.002

Holtom, B., Mitchell, T., Lee, T., \& Inderrieden, E. (2005). Shocks as causes of turnover: What they are and how organizations can manage them. Human Resource Management, 44(3), 337-352. https://doi.org/10.1002/hrm.20074

Hu, Q., Schaufeli, W., \& Taris, T. (2017). How are changes in exposure to job demands and job resources related to burnout and engagement? A longitudinal study among Chinese nurses and police officers. Stress and Health, 33(5), 631-644. https://doi.org/10.1002/smi.2750

Jackson, S., Schwab, R., \& Schuler, R. (1986). Toward an understanding of the burnout phenomenon. Journal of Applied Psychology, 71(4), 630-640. https://doi. org/10.1037/0021-9010.71.4.630

Jennings, B.M. (2008). Restructuring and mergers. In R.G. Hughes (Ed.). Patient safety and quality: An evidence-based handbook for nurses (pp. 1-17). Rockville, MD: AHRQ.

Kaatz, J., French, P., \& Prentiss-Cooper, H. (1999). City council conflict as a cause of psychological burnout and voluntary turnover among city managers. State an Local Government Review, 31(3), 162-172. https://doi.org/10.1177/01603 23X9903100302

Kartono, K., \& Hilmiana, H. (2018). Job burnout: A mediation between emotional intelligence and turnover intention. Jurnal Bisnis dan Manajemen, 19(2), 109-121. https://doi.org/10.24198/jbm.v19i2.189

Kim, Y. (2016). Music therapists' job demands, job autonomy, social support, and their relationship with burnout and turnover intention. The Arts in Psychotherapy, 51 17-23. https://doi.org/10.1016/j.aip.2016.08.001

Krishnan, S., \& Singh, M. (2010). Outcomes of intention to quit of Indian IT professionals. Human Resource Management, 49(3), 421-437. https://doi. org/10.1002/hrm.20357

Lee, R., \& Ashforth, B. (1993). A longitudinal study of burnout among supervisors and managers: Comparisons between the Leiter and Maslach (1988) and Golembiewski et al. (1986) models. Organizational Behavior and Human Decision Processes, 54(3), 369-398. https://doi.org/10.1006/obhd.1993.1016

Lee, Y., \& Eissenstat, S. (2018). A longitudinal examination of the causes and effects of burnout based on the job demands-resources model. International Journal for Educational and Vocational Guidance, 18, 337-354. https://doi.org/10.1007/ s10775-018-9364-7

Lee, T.W., \& Mitchell, T.R. (1994). An alternative approach: The unfolding model of voluntary employee turnover. Academy of Management Review, 19(1), 51-89. https://doi.org/10.2307/258835

Leiter, M., \& Harvie, P. (1997). Correspondence of supervisor and subordinate perspectives during major organizational change. Journal of Occupational Health Psychology, 2(4), 343-352. https://doi.org/10.1037/1076-8998.2.4.343

Leiter, M., \& Harvie, P. (1998). Conditions for staff acceptance of organizational change: Burnout as a mediating construct. Anxiety, Stress, and Coping, 11(1) 1-25. https://doi.org/10.1080/10615809808249311

Lin, Q., Jiang, C., \& Lam, T.H. (2013). The relationship between occupational stress, burnout, and turnover intention among managerial staff from a Sino-Japanese joint venture in Guangzhou, China. Journal of Occupational Health, 55(6), 458-467. https://doi.org/10.1539/joh.12-0287-oa

Linde, B., \& Schalk, R. (2006). Experience of the employment relationship after a merger. Management Revue, 17(4), 484-498. http://hdl.handle.net/10419/78912

Martin, T.N. (1979). A contextual model of employee turnover intentions. Academy of Management Journal, 22(2), 313-324. https://doi.org/10.5465/255592

Maslach, C., \& Goldberg, J. (1998). Prevention of burnout: New perspectives. Applied \& Preventive Psychology, 7(1), 63-74. https://doi.org/10.1016/S0962-1849 (98)80022-X

Maslach, C., Jackson, S.E., \& Leiter, M.P. (1996). Maslach burnout inventory manual (3rd edn.). Palo Alto, CA: Consulting Psychologists Press.
Maslach, C., \& Leiter, M. (2008). Early predictors of job burnout and engagement. Journal of Applied Psychology, 93(3), 498-512. https://doi.org/10.1037/0021 9010.93.3.498

Maslach, C., \& Leiter, M. (2016). Understanding the burnout experience: Recent research and its implications for psychiatry. World Psychiatry, 15(2), 103-111. https://doi.org/10.1002/wps.20311

Maslach, C., Schaufeli, W., \& Leiter, M. (2001). Job burnout. Annual Review of Psychology, 52, 397-422. https://doi.org/10.1146/annurev.psych.52.1.397

Moore, J. (2000). One road to turnover: An examination of work exhaustion in technology professionals. MIS Quarterly, 24(1), 141-168. https://doi.org/10.2307/3250982

Mor Barak, M.E., Nissly, J.A., \& Levin, A. (2001). Antecedents to retention and turnover among child welfare, social work, and other human service employees: What can we learn from past research? A review and metanalysis. The Social Service Review, 75(4), 625-661. https://doi.org/10.1086/323166

Morrell, K., Loan-Clarke, J., \& Wilkinson, A. (2001). Unweaving leaving: The use of models in the management of employee turnover. International Journal of Management Reviews, 3(3), 219-244. https://doi.org/10.1111/1468-2370.00065

Ndetei, D., Pizzo, M., Maru, H., Ongecha, F., Khasakhala, L., Mutiso, V., \& Kokonya, D. (2008). Burnout in staff working at the Mathari psychiatric hospital. African Journal of Psychiatry, 11(3), 199-203. https://doi.org/10.4314/ajpsy.v11i3.30269

Nunnally, J., \& Bernstein, L. (1994). Psychometric theory. New York, NY: McGraw-Hill.

Pines, A.M. (2002). The changing psychological contract at work and employee burnout. Journal of Health and Human Services Administration, 25(1), 11-32. Retrieved from https://www.ncbi.nlm.nih.gov/pubmed/15137566

Rothmann, S., \& Joubert, J. (2007). Job demands, job resources, burnout and work engagement of managers at a platinum mine in the North West Province. South African Journal of Business Management, 38(3), 49-61. https://doi.org/10.4102/ sajbm.v38i3.588

Rouse, P.D. (2001). Voluntary turnover related to information technology professionals: A review of rational and instinctual models. The International Journal of Organizational Analysis, 9(3), 281-290. https://doi.org/10.1108/eb028937

Rousseau, D. (1995). Psychological contracts in organizations: Understanding written and unwritten agreements. Thousand Oaks, CA: Sage.

Santoso, A.L., Sitompul, S.A., \& Budiatmanto, A. (2018). Burnout, organizational commitment and turnover intention. Journal of Business and Retail Management Research, 13(1), 62-69. https://doi.org/10.24052/JBRMR/V13IS01/ART-06

Scanlan, J., \& Still, M. (2013). Job satisfaction, burnout and turnover intention in occupational therapists working in mental health. Australian Occupationa Therapy Journal, 60(5), 310-318. https://doi.org/10.1111/1440-1630.12067

Schaufeli, W.B. (2003). Past performance and future perspectives of burnout research. SA Journal of Industrial Psychology, 29(4), 1-15. https://doi.org/10.4102/sajip.v29i4.127

Schaufeli, W.B., \& Greenglass, E.R. (2001). Introduction to special issue on burnout and health. Psychology and Health, 16(5), 501-510. https://doi. org/10.1080/08870440108405523

Schaufeli, W., \& Van Dierendonck, D. (1993). The construct validity of two burnout measures. Journal of Organizational Behavior, 14(7), 631-647. https://doi. org/10.1002/job.4030140703

Seeletse, S. (2001). Sampling devotion for efficient and effective representative sample surveys. Pakistan Journal of Applied Sciences, 1(4), 504-507. https://doi org/10.3923/jas.2001.504.507

Shah, P.P. (2000). Network destruction: The structural implications of downsizing. Academy of Management Journal, 43(1), 101-112. https://doi. org/10.5465/1556389

Staw, B.M. (1980). The consequences of turnover. Journal of Occupational Behaviour, 1(4), 253-273. https://www.jstor.org/stable/3000143

Torkzadeh, G., \& Dhillon, G. (2002). Measuring factors that influence the success of internet commerce. Information Systems Research, 13(2), 187-204. https://doi. org/10.1287/isre.13.2.187.87

Visser, W., \& Rothmann, S. (2008). Exploring antecedents and consequences of burnout in a call centre. SA Journal of Industrial Psychology, 34(2), 79-87. https:// doi.org/10.4102/sajip.v34i2.734

Wang, Y., Huang, J., \& You, X. (2016). Personal resources influence job demands, resources, and burnout: A one-year, three-wave longitudinal study. Social Behavior and Personality: An International Journal, 44(2), 247-258. https://doi. org/10.2224/sbp.2016.44.2.247

Weisberg, J. (1994). Measuring workers' burnout and intention to leave. International Journal of Manpower, 15(1), 4-14. https://doi.org/10.1108/01437729410053590 